Available online on 15.02.2020 at http://jddtonline.info
Open Access to Pharmaceutical and Medical Research
unrestricted non-commercial use, provided the original work is properly cited

Open $\odot$ Access

Research Article

\title{
Epidemiological Approach and Precocious Diagnosis of Precancerous Cervical Lesion in Sidi Bel Abbes Region (North-West of Algeria)
}

\author{
Samira Meziani ${ }^{* 1}$, Khadidja Haoud ${ }^{1}$, Hayet Mehida ${ }^{1}$, Norreddine Menadi ${ }^{1}$, Fatima Zohra Chenni ${ }^{1}$, \\ Imene Bekhaled', Fatima Zohra Drici'2, Abassia Demmouche' ${ }^{1}$, Mohammed Benali ${ }^{1}$ \\ 1 Laboratory of Biotoxicology. Department of Biology-Faculty of Life Science and Nature. Djillali Liabes University. Sidi-Bel-Abbes, Algeria \\ 2. Laboratory of Ana-pathology of Sidi-Bel-Abbés, Algeria
}

\begin{abstract}
Object: Cervical cancer of the uterine (CCU) is the first cancer of the genital tract. In Algeria, this cancer remains a real public health problem. The diagnosis is still done often with advanced stages which makes the therapeutic results modest and the cost of the high care. Methodology: Our study aims to elucidate the reality of this type of pathology in the region of Sidi Bel Abbes, northwestern Algeria. This retrospective and descriptive study was devoted to the epidemiological and clinical analysis of cervical cancer cases over a period of 3 years. Results: This study shows that out of a total of 500 smears recorded between (2014-2016) at the Ana-pathology laboratory level in Sidi Bel Abbes, we found that 230 smears presented precancerous lesions according to a cytological study, atypical squamous cells of undetermined significance (ASC-US: were 18\%; low-grade squamous intraepithelial lesions (LSIL) were 20\%, while high-grade squamous intraepithelial lesions (HSIL) were $8 \%$. The results obtained according to the distribution of the patients in relation to the various factors: the most affected age group is late $46-55$ years with a total of $40 \%$; precocious age of 1 st report $18-20$ years is (38.2\%); gestation 4-5 pregnancies and parities $4-5$ children with a rate of $(38.70 \%$ and $32.6 \%)$ respectively ; the hormonal state in genital activity is estimated at $62.2 \%$; patients on oral contraception (OC) have a rate of $48.9 \%$. Finally, more than half of the patients (57.8\%), were able to have a biopsy within three to four months of the last smear.
\end{abstract}

In histology, the presence of a HPV (Human Papilloma Virus) low grade lesion does not predict the evolution of this lesion. Conclusion: HPV can be oncogenic or non-oncogenic. it is the oncogenic HPV infection that is the main risk factor for developing a high grade lesion and cervical cancers outside the associated cofactors.

Keywords: Pap Smear, Precancerous lesion, Cancer, Cervix, Screening

Article Info: Received 21 Nov 2019; Review Completed 16 Jan 2020; Accepted 26 Jan 2020; Available online 15 Feb 2020

Cite this article as:

Meziani S, Haoud K, Mehida H, Menadi N, Chenni FZ, Bekhaled I, Drici FZ, Demmouche A, Benali M, Epidemiological Approach and Precocious Diagnosis of Precancerous Cervical Lesion in Sidi Bel Abbes Region (North-West of Algeria), Journal of Drug Delivery and Therapeutics. 2020; 10(1-s):72-78 http://dx.doi.org/10.22270/jddt.v10i1-s.3862

*Address for Correspondence:

Samira Meziani. Doctor of Biology at Djillali Liabes University, Laboratory of Biotoxicology. Department of Biology-Faculty of Life Science and Nature. Djillali Liabes University. Sidi bel abbes. Algeria

\section{INTRODUCTION}

Worldwide, utérine cervix cancer (UCC) is the second gynecological cancer in Algeria, with an incidence of 8.7 per 100,000 women. It accounts for $12.5 \%$ of all female cancers according to the national survey conducted by the National Institute of Public Health in Algeria [1]. It is the fourth leading cause of cancer death in women, with 266,000 deaths in 2012 [2]. It has been suggested that healthy women are more likely to be screened for UCC [3]. Early detection of precancerous lesions remains, as a result, the main axis of the fight against the disease which must not, therefore, not be a death sentence, even in poor countries. Low-cost screening tools and low technology exist today, they could significantly reduce the burden of cervical cancer deaths in these countries [4].

Cervical infections with Human Papilloma Virus (HPV) are considered as the first cause of UCC [5]. The infection is asymptomatic and transient in the vast majority of cases. Viruses are eliminated in $80 \%$ of cases in 8 to 12 months. In the remaining $20 \%$ of cases, the infection persists with the appearance of lesions which eventually regress to a large extent. Patients who can not get rid of called viruses. Oncogenes have an increased risk of developing a preinvasive lesion or cervical cancer. The different progress made in molecular biology has led to the development of vaccines and screening tests that could give hope for better prevention of invasive cervical cancer. In 2008, Algeria ranks 
third among Arab countries in terms of prevalence of this cancer. The relatively high prevalence of cases in Algeria is due to several risk factors [6]. A program to fight against UCC has been launched in Algeria since 2001. In this study, we conducted an epidemiological and retrospective survey of 230 UCC cases in this work, the experience at the Sidi Bel Abbes pathology laboratory level, over an extended 03-year period from 2014-2016.

Today, no evaluation of these actions has been made at the level of the Sidi Bel Abbes wilaya, thus, it seemed to us interesting to carry out a study of the prevalence of cervical dysplasias in this region, because of its disposition of a developed screening laboratory.

\section{MATERIALS AND METHODS}

\section{II.1. Study population}

II. Our work consisted of a retrospective study from 2014 to 2016 on a population of women who visited the cervico-vaginal smear screening unit at the Anatomy and Pathology Cytology laboratory at SBA. The main parameters used were: Age of first report, distribution of cytological lesions by age group, parity, , the number of smears by people, the duration between the last smear and the biopsy, the appearance of the cervix before the smear and histological control. Data was collected based on exam records and analysis done on Excel. From this material we selected 500 smears, including 140 inflammatory smears, 230 smears with low and high grade squamous lesions; the latter were checked and selected for sampling and for a cytological and histological study.

\section{II.2. La Cytologie et la réalisation de FCU (frottis cervico- utérins)}

Screening smear was unexpectedly performed in unruly women presenting at the consultation for any reason of gyneco-obstetrics, monitoring a pregnancy, prescribing a contraceptive and setting up an intrauterine device. For these cases, the smear was performed on any day of the cycle except for the menstrual period; each woman received a gynecological examination. The external genitalia were examined for inflammations, or unusual flow. The appearance of the cervix is controlled and all anomalies are noted namely, vaginal discharge, inflammatory aspect, ulcerations, vesicles, bleeding on contact, neck frankly tumoral. We gathered for the period 2014-2015 and 2016 cervical-uterine smears, performed as part of screening for precancerous cervical lesions; they come to us from routine consultations with gynecologists and samplers of SBA Maternity, Health sectors at the level of wilaya of SBA and Private sector.

The smears are retained with lesions of ASC-US, LSIL, and HSIL (Table 1) that are classified according to the Bethesda 2001 system.

\section{II.3. The Histology}

Patients with ASC-US, LISL and HSIL smears are referred to colposcopy for colposcopic examination and biopsy. Some of these patients who presented with special signs such as metrorrhagia had staged curettage without colposcopy. After the biopsy, the samples are most often fixed with $9 \%$ diluted formalin. The staining associates a nuclear dye, Harris hematoxylin to cytoplasmic dyes, the orange $G$ and the polychrome mixture $\mathrm{EA}_{50}$ of Papanicola, or. A macroscopic examination and histological analysis were performed in this study (nuclei, basophils in purple, acidophilic cytoplasm, pink muscles, erythrocytes and collagen). A judgment is made on the cell richness and the technical quality of the smear.

In order to standardize the results, the interpretation was made according to the Bethesda 2001 system.

\section{Results and discussions}

\section{I. RESULTS}

\section{III.I.1.Results of cytological diagnosis}

Among 500 smears recorded, 140 correspond to inflammatory smears and 130 without particularities, 230 smears bearing precancerous lesions. In our study, we used patient records from 2014 to 2016. A qualitative analysis was described in terms of percentage ASC-US lesions are reactional changes, repair processes or atrophies and other lesions, are intraepithelial of indeterminate variable grade. In our study, These lesions represent $18 \%$ of the cases in our series. Figure 1 shows a microscopic observation of ASC-US type smears. Regarding low-grade squamous intraepithelial lesions (LISL), we find that nearly half of the smears in our series, 20\% are low-grade squamous intraepithelial lesions. Cytology shows the presence of undifferentiated cells and intermediate squamous cells with an often homogeneous hyper-chromatic nucleus increased in volume (Figure 1). We also note the presence of koilocytic cells crumpled retracted nucleus surrounded by a clear halo, he cytoplasm presents it self as a dense cynophilic or eosinophilic border. This aspect of the nucleus is due to the presence of HPV. Results obtained for high-grade squamous intraepithelial lesions (HSIL), indicate that this type of lesion is a squamous intraepithelial squamous epidermoid lesion which represents in this study $08 \%$ of patients' cases. Figure 1 shows the cytology of the high-grade lesions which is characterized by: the presence of large nucleus relative to the rest of the cell which evokes a very high nucleocyclic ratio or inverted, eosinophilic, keratinized or basophilic cytoplasm, chromatin in coarser granulations often poorly distributed, hyper colored marginate or mottée, the nucleoli are visible, the nuclear membrane is strongly indented and thickened and the well-differentiated forms, often keratinizing, indicate dysplastic cells characterized by a more abundant cytoplasm and dyskeratosis with fiber cells.

Table 1 : Percentage of Cytologic Abnormalities Diagnosed and Classified by Bethesda 2001 System

\begin{tabular}{|c|c|c|c|c|c|}
\hline Cytology diagnosis & 2014 & 2015 & 2016 & Number de cases & Percentage \% \\
\hline ASC-US & 28 & 41 & 21 & 90 & 18 \\
\hline LISL & 9 & 31 & 60 & 100 & 20 \\
\hline HSIL & 7 & 15 & 18 & 40 & 08 \\
\hline Normal & I & / & I & 130 & 26 \\
\hline Inflammatory & / & I & l & 140 & 28 \\
\hline
\end{tabular}




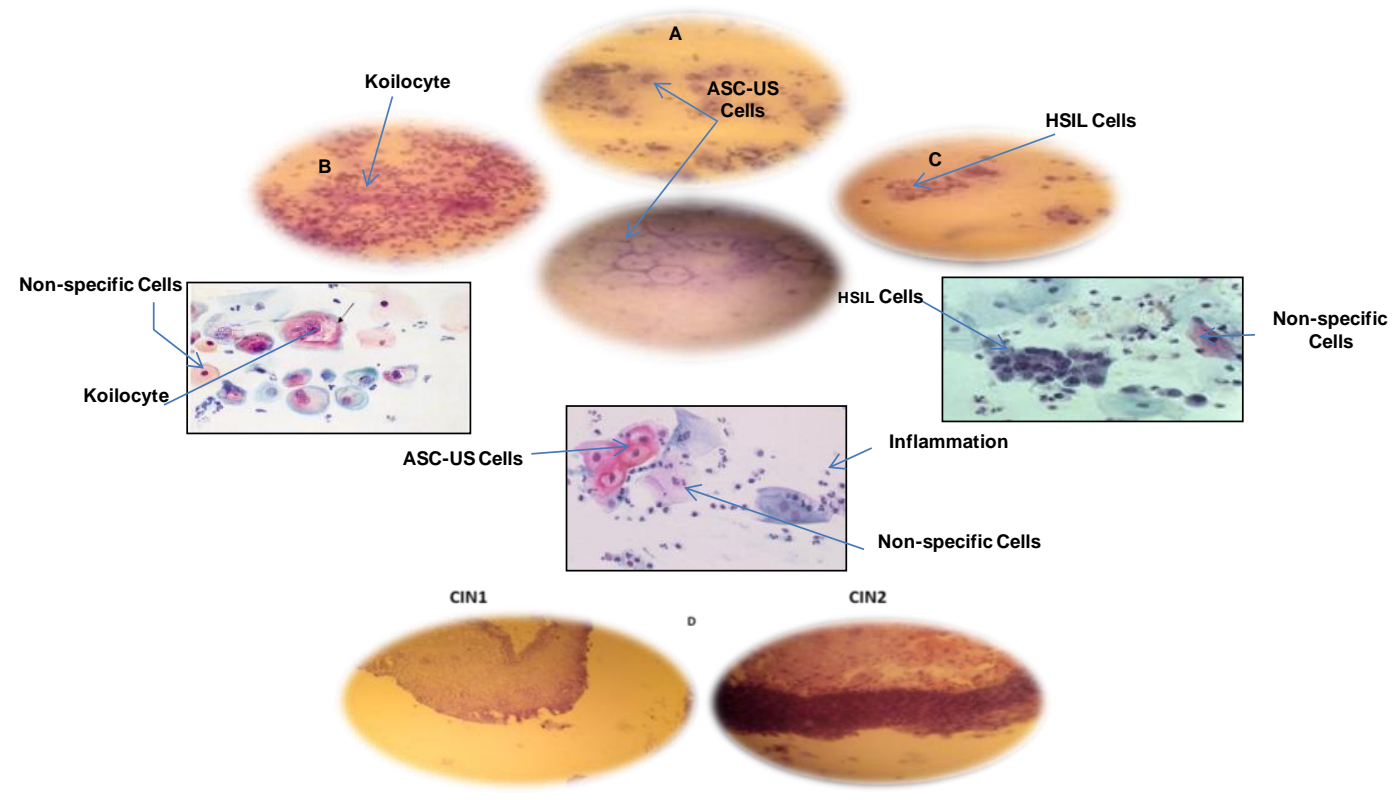

Fig 1: Example of microscopic observation of smear type (A) type (ASC-US), increased volume core 2.5x the size of an intermediate cell, slightly dense chromatin, thin nuclear membrane (x200). (B) Low-grade epithelial lesion (LISL), Koycytic Cells (arrow) Papinicola (x400). (C) High-grade epithelial lesion (HSIL), (CIN2-CIN3) and HPV-type infection (x400). (D)Histological diagnosis of a low-grade intra-epithelial (CIN1) and high-grade malpighelial lesion (CIN2 and CIN3) with HPVtypeinfection

ASC-US: Atypical Malpighian Cells

LISL: Low-grade intra-epithelial Malpighian lesion

HSIL: High-guard intra-ethelial Malpigheal Epidermoid Lesion

CIN1: Low-grade intra-epithelial Malpighelial injury.

CIN2 and CIN3: High-grade intra-epithelial Malpighelial lesion.

\section{III.1.2.Association of patients with respect to different parameters}

The distribution of cytology lesions by age group showed that the lesions are observed from 26 years old with a frequency peak in the age group 46-55 years, afterwards this frequency of lesions diminished with age (Table 2).

In the same age group, we observed that ASC-US lesions accounted for $41 \%$ of cases, while LSIL accounted for $43 \%$ of cases. The extreme ages are 25 and 65 years, more than one third of the patients are in the age groups 36-45 years and 46-55 years; it is the most affected age group with a total of 75 cases, $32.61 \%$ and 91 cases, or $40 \%$, respectively. Women under 35 and over 55 years of age are less represented $(15.22 \%-8.26 \%)$ according to this study, while patients aged over 65 accounted for only $4.35 \%$ of cases, or 10 cases in total. In all cases, the proportion of patients married before or at age 15 and after age 25 is $7 \%$ and $6.5 \%$, respectively; that of married women aged between 18-20 and $21-25$ years is $38.2 \%$ and $36.1 \%$ respectively (Table 3 ). According to the hormonal status, more than $50 \%$ of women are cases in genital activity, the other half of women were either peri-menopausal or menopausal at diagnosis.

The results of pregnancy and parity in our patients show that more than $1 / 3$ of patients have 6 or more children. Women who are in genital activity and who are generally on oral contraception (OC) account for $48.9 \%$, while $17.4 \%$ of patients have either an intrauterine device (IUD), or local contraception (Cl), in $11.8 \%$ of patients, the use or not of a contraceptive method was not specified. According to our results $45.2 \%$ of women in a single cervico-vaginal smear in their lives, $30.4 \%$ have two smears and $6.6 \%$ do not give precision (NP).

Regarding the time interval between the last smear and the biopsy, more than half of the patients $(57.8 \%)$ were able to have a biopsy within three to four months of the last smear (Table 3). Most of the patients had a pathological neck; of which $65.6 \%$ were an inflammatory cervix, $10.4 \%$ of cases, women had contact bleeding; and finally, $24 \%$ of cases it was a clean collar.

Table 2: Distribution of patients in relation to the presence of cytological lesions and by age group

\begin{tabular}{|l|c|c|c|c|}
\hline Age & ASC-US & LSIL & HSIL & Average \\
\hline$\leq \mathbf{2 5}$ Years & 0 & 0 & 0 & 0.00 \\
\hline 26-35 Years & 15 & 14 & 2 & 10.33 \\
\hline 36-45 Years & $\mathbf{2 9}$ & $\mathbf{3 1}$ & $\mathbf{1 3}$ & $\mathbf{2 4 . 3 3}$ \\
\hline 46-55 Years & $\mathbf{4 1}$ & $\mathbf{4 3}$ & $\mathbf{1 5}$ & $\mathbf{3 3 . 0 0}$ \\
\hline 56-65 Years & 3 & 10 & 8 & 7.00 \\
\hline$\geq 65$ Years & 2 & 2 & 2 & 2.00 \\
\hline
\end{tabular}

ASC-US: Atypical Malpighian Cells

LISL: Low-grade intra-epithelial Malpighian lesion

HSIL: High-guard intra-ethelial Malpigheal Epidermoid Lesion 
Table 3: Distribution in (\%) of the patients in relation to the different parameters

\begin{tabular}{|c|c|c|}
\hline Setting & Numbre des cases & $\%$ \\
\hline $\begin{array}{l}\text { Age range } \\
\leq 25 \text { years } \\
26-35 \text { years } \\
36-45 \text { years } \\
46-55 \text { years } \\
56-65 \text { years } \\
\geq 65 \text { years }\end{array}$ & $\begin{array}{l}00 \\
35 \\
75 \\
\mathbf{9 1} \\
19 \\
10\end{array}$ & $\begin{array}{c}00 \\
15.22 \\
32.61 \\
\mathbf{3 9 . 5 7} \\
8.26 \\
4.35\end{array}$ \\
\hline $\begin{array}{l}\text { 1st report age } \\
\leq 15 \text { years } \\
16-17 \text { years } \\
18-20 \text { years } \\
21-25 \text { years } \\
\geq 25 \text { years }\end{array}$ & $\begin{array}{l}16 \\
28 \\
88 \\
83 \\
15\end{array}$ & $\begin{array}{c}7 \\
12.2 \\
38.2 \\
36.1 \\
6.5\end{array}$ \\
\hline $\begin{array}{l}\text { Hormonal status } \\
\text { Genital activity } \\
\text { Perimenopause } \\
\text { Menopause }\end{array}$ & $\begin{array}{c}143 \\
54 \\
33\end{array}$ & $\begin{array}{l}\mathbf{6 2 , 2} \\
23.5 \\
14.3\end{array}$ \\
\hline $\begin{array}{l}\text { Gestational } \\
\leq 1 \\
1-3 \\
4-5 \\
6-7 \\
8-9 \\
\geq 10\end{array}$ & $\begin{array}{c}2 \\
62 \\
89 \\
35 \\
33 \\
09\end{array}$ & $\begin{array}{c}0.87 \\
26.96 \\
\mathbf{3 8 . 7 0} \\
15.22 \\
14.35 \\
3.91\end{array}$ \\
\hline $\begin{array}{l}\text { Contraception } \\
\text { CO } \\
\text { DIU } \\
\text { CL } \\
\text { Unspecified }\end{array}$ & $\begin{array}{l}70 \\
25 \\
17 \\
31\end{array}$ & $\begin{array}{l}\mathbf{4 8 . 9} \\
17.4 \\
11.8 \\
21.6\end{array}$ \\
\hline $\begin{array}{l}\text { Number smear } \\
1 \\
2 \\
3 \\
>3 \\
\text { NP }\end{array}$ & $\begin{array}{c}\mathbf{1 0 4} \\
70 \\
36 \\
5 \\
15\end{array}$ & $\begin{array}{c}45.2 \\
30.4 \\
15.6 \\
2.2 \\
6.6\end{array}$ \\
\hline $\begin{array}{l}\text { Time interval } \\
\leq 3 \\
3-4 \\
5-6 \\
7-8 \\
9-12 \\
\geq 12\end{array}$ & $\begin{array}{c}62 \\
133 \\
20 \\
8 \\
7 \\
0\end{array}$ & $\begin{array}{c}27 \\
\mathbf{5 7 . 8} \\
8.7 \\
3.5 \\
3 \\
0\end{array}$ \\
\hline $\begin{array}{l}\text { Cervix aspect } \\
\text { Healthy } \\
\text { Inflammatory } \\
\text { Bleeding }\end{array}$ & $\begin{array}{c}55 \\
\mathbf{1 5 1} \\
24\end{array}$ & $\begin{array}{c}24 \\
\mathbf{6 5 . 5} \\
10.5\end{array}$ \\
\hline
\end{tabular}

\section{III.1.3. Histological control}

For all our patients and whatever the appearance of the cervix and the type of abnormalities found in the smear, a colposcopic examination with the biopsy was requested. The majority of the patients benefited from colposcopy: 07 cases or $3 \%$ have insufficient samples; 12 cases $(5.1 \%)$ are without particularity; 71 cases (30.9\%) have an inflammatory, metaplastic, and atrophic or polyp aspect and 140 cases $(60.9 \%)$ have HPV-related lesions (Figure 2).The cyto-histological concordance concerning our serial and evaluated at $90 \%$ (screening and colposcopic results with biopsy). 


\section{Histological diagnosis}

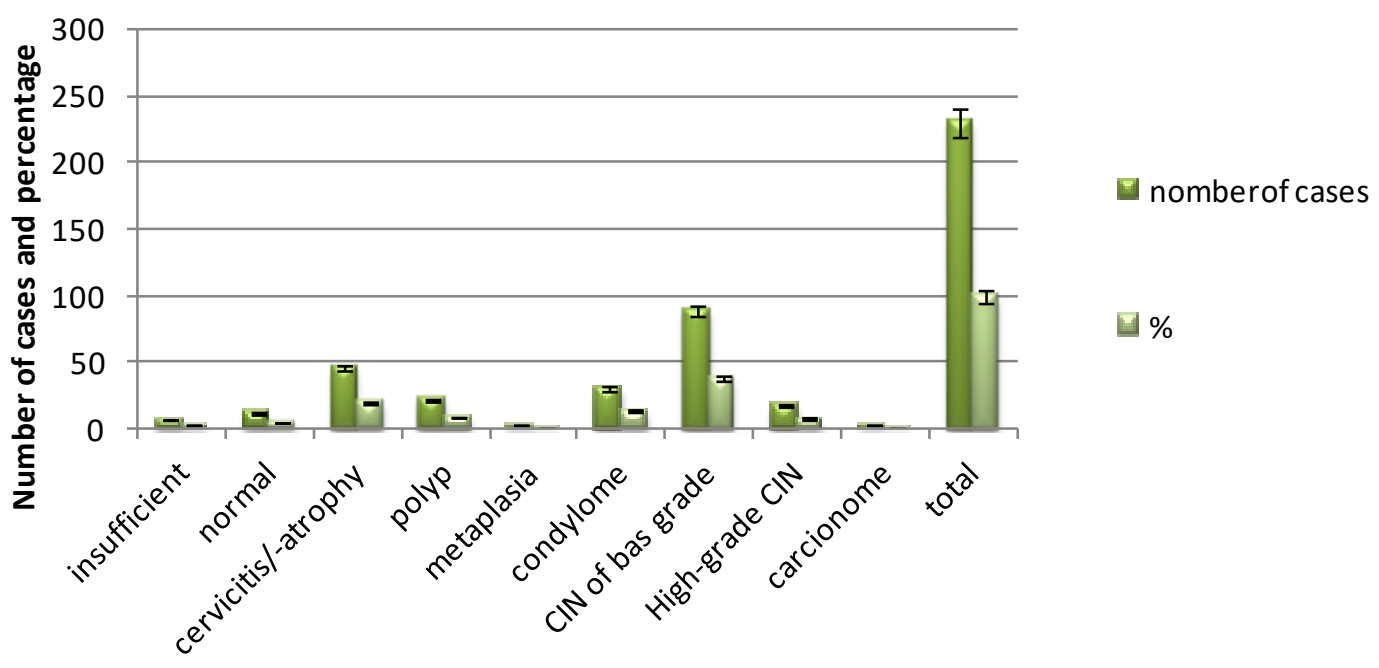

histological diagnosis

Fig 2: Percentage histological diagnosis (\%) patients with different abnormalities.

Regarding low-grade squamous intraepithelial lesion (CIN1), the microscopic examination shows an exocervical mucosa with a koilocyte surface coating, cellular disorganization with the presence of nuclei. While high-grade intraepithelial lesions (CIN2 and CIN3), superficial exocervical-coated patches are at the level of the surface layer of architectural disorganization with a disturbance in cell maturation and differentiation that in some places exceeds $2 / 3$ of the height of the coating with some figures of atypical mitoses (Figure 1), presence of koilocytes.

\section{III.2. DISCUSSIONS}

The study covered 500 smears during 03 years (2014-2016). In this work, we selected 230 cervico-vaginal smears (CVS) with pre-cancerous lesions. We remind that in general, the woman only presents herself after one or more pregnancies. $90.4 \%$ of women do not know the importance of CVS according to the [7] study.

The majority of benign cellular changes such as the ASC-US case; nevertheless, 5 to $17 \%$ of high-grade intraepithelial lesions are found according to [8], the ASC-H group comprises approximately 50 to $80 \%$ of high-grade intraepithelial lesions [9]. In difficult cases, the cytopathologist proposes either to repeat the smear test estrogen, hormone replacement impregnation mitigates trophic cell damage, to better distinguish dystrophic changes, lesion changes, or to colposcopy.According to the distribution of cytological lesions by age group.

In our series a single peak of HPV cytological lesions was found between 46 and 55 years of age (Table 2); in the literature, there is little study on the age distribution of HPVrelated cytological lesions.

The woman only consults for the first smear after the marriage, usually well after the first pregnancy. In our series, among women whose age range is between 26 and 65 years old, low-grade cytological abnormalities regress frequently and decrease after this age, and the high-grade cytological abnormalities correspond to $20 \%$ of the cases in our series. In the study of [7], indicate that $95.5 \%$ of women have the first smear from age 40 , our results may be biased by late consultation for smear practice. Age plays an important role for most authors.

In the study [10], the most represented age group is 46 and over with $37.9 \%$, the $36-45$ age group represented $34.7 \%$ and $25-35$ years, $27.4 \%$, with extreme 25 to 87 years old. The average age of diagnosis is 54 years according to the Directorate General of Health Structures in Algeria (DGSSA), 2016. The occurrence of metrorrhagia caused by sexual intercourse or the vaginal toilet must evoke a cervical lesion. Sometimes cancer of the cervix is revealed by leucorrhea associated with blood. We have found from our series (Table 3 ) that patients with cervical lesions are women who are married for the most part after 16 years (peak between 1820 years) or $38.2 \%$. The distribution of women by age is an important factor, where the influence of age at first report on the risk of acquisition of HPV infection and consequently the risk of developing high-grade lesions and of cancer that have been regularly cited in several works.

The adolescent's cervix is both more exposed to infections and more vulnerable because of the physiological eversion of the glandular mucosa (monolayer epithelium more exposed to the gaps allowing the entry of the virus). According to the study conducted by [11] found a marked precocity to marriage, as $62.3 \%$ are married before the age of 17, a study conducted in Burkina Faso reports $63.80 \%$ of early marriage to 16 years or earlier, we find that women who had their first relationship between 15 and 17 years have a risk doubled according to the study conducted by [12] .The analysis according to [7] showed a three-fold higher risk among married women between 18 and 20 years old. In the case of the distribution of women by pregnancy and parity, we found in this study (Table 3 ) that $32.6 \%$ of patients are multiparous (4-5 pregnancies or more), the nulliparous rate is $\leq$ at $2.2 \%$, whereas, [7], found in its series of 209 cases of CCU, a high risk in women with 7 or more children.

His findings found against the literature of [13], that multiparous women had a fourfold higher risk of developing squamous lesions. The large multiparity linked to a large multi-Gestity appears as a risk factor. 
Some authors consider it a co-factor related to uncontrolled sexual activity or unplanned maternity. An epidemiological survey conducted under the auspices of the World Health Organization (WHO) attributes to oral contraception for more than 8 years a risk of cervical cancer multiplied by 2.2 . For intraepithelial lesions, the effect appears to be less important, even nil or protective [14]. Another study considers that gestationality is a risk factor in its own right, implying the physiological repercussions of the evolution of pregnancy. on the mechanisms of local immune defenses linked to the biological upheaval experienced by the cervical epithelium [15]. Relative risk in women who have completed 07 or more Pregnancies. Concerning choice of contraception (Table 3), he results showed that $48.9 \%$ of the women are in genital activity and have a lesion smear that has been under oral contraception.

The duration of contraception has not been evaluated. The choice of the contraceptive method also seems to affect the risk of CCU. The barrier-type method seems to reduce the risks, while oral contraceptives seem to increase it. The risk associated with oral contraceptives seems to be greater for adenocarcinoma than for squamous cell carcinoma, even after adjusting for different socio-economic and sexual factors [16]. More than $50 \%$, that is to say $65 \%$ of patients under oral contraception of which $62 \%$ since more than 05 years according to [17]; and a duration of four to eight years for women have a rate of $45.5 \%$ or $31.5 \%$ with oral contraception. [7]. A meta-analysis of 24 international epidemiological studies confirms a total of 52,000 women, an association between taking oral contraceptives and precancerous lesions or invasive cancer. This study shows that the risk of cancer increases with the duration of use of the pill, a relative risk of 1.9 for a catch of at least 05 years compared to those that have never been used. The results obtained on the hormonal state parameter (Table 3) and a precancerous lesion showed that more than $50 \%$ of women are cases in genital activity,

the other half of women are either peri-menopausal or menopausal. His women accounted for $40.7 \%$ in their series; and among them the invasive cancer was found in $75.0 \%$ according to a study conducted by [10]. Regarding the appearance of the cervix smear, the results show that in our series (Table 3) most of the patients had a pathological neck; in $65.6 \%$ it was an inflammatory cervix. The foul-smelling leucorrhea and scratch-off lesions that are evidence of genital infection are described as a co-risk factor for cervical cancer in their chronic appearance, and they were reported proportionally by $84.7 \%$ and $58.1 \%$ of their studies, and who had a high LEL, unlike invasive cancer, which was relatively more common among women who did not report this history [10]. In our study almost half (45.2\%) had a single cervico-vaginal smear. The international recommendations specify that the first smear must be done one year after the first sexual intercourse, the second to one year later in the absence of anomaly. This recommendation is based on the very slow evolution of precancerous lesions and statistical models show that smears performed every three years allow the detection of $93 \%$ of CCU. For that, a biopsy is necessary to evaluate the risk of the beginning of cancer. According to our study conducted on 230 cases, or $57.8 \%$ having the biopsy in a duration of 3-4 months of the last smear, this allowed to have the image more or less exact of the lesion without it being modified by evolution in time. $\mathrm{n}$ this case, colposcopic control is mandatory in the event of an ASC-US, LISL and HISL abnormal smear, which must be done before 6 months, also before LISL and when the chosen option is colposcopy the practice of the latter must not exceed 6 months [18]. Colposcopy has interested sexually active women from the age of 20 , with a predominance of women over 50 years old. . Cervical cancer screening should be offered to all sexually active women from the age of 20 $[12 ; 19]$. We have been able in most cases to respect the time interval of less than 06 months between the last smear and the biopsy.

Finally the histological diagnosis manages to select a rate of $8 \%$ of high-grade lesions, $1.3 \%$ infiltrating cancers and $38.6 \%$ low-grade lesions; testifying on the one hand of the good application of the cytological criteria of LSIL of the Bethesda system, on the other hand cytology is relatively easy LSIL.In Algeria, Women with LISL lesions are most often controlled by initial colposcopy when possible. Moreover, LISL and as we have seen in the literature can hide high-grade lesions or invasive carcinomas, the control of all LISLs by colposcopy with or without histology makes it possible to identify these high-grade lesions and to avoid the risk of evading follow-up, but this can weigh heavily economically and time.

Specificity is also increased by the combination of the HPV test. On can be seen from our results that cytological abnormalities regress frequently and decrease with age, which explains why the incidence of HPV infections decreases with the age of women.

\section{CONCLUSION}

The Cervical Cancer in the Uterine (CCU) is probably the cancer whose screening would be the most contributive if it were conducted under favorable conditions. While everyone recognizes the legitimacy of this screening and its effectiveness, the terms of its organization for mass screening still create differences. At the end of our study, it seems clear that the conventional smear remains the only weapon to detect cervical cancer at its beginning. to introduce a treatment that is not or not mutilating and thus ensure the highest possible survival rate. Visual inspection methods are simple, inexpensive, and therefore affordable for developing countries; to effectively detect precancerous lesions of the cervix. Colposcopy is the key examination of the diagnosis of high-grade cervical lesions; it guides biopsies by locating the most suspect areas of cancer.

Conflicts of interest: Authors declare no conflict of interests.

Acknowledgements : Authors want to thank the staff of Biology. Department of Sidi-Bel-Abbes Unversity, especially. Biotoxicology laboratory, and, for valuable assistance in this study.

\section{REFERENCES}

[1]. INSP National Institute of Public Health in Algeria. Algiers Tumor Registry, 2010.

[2] Saadi A, Tazi MA, Er-raki A. Cervical cancer survival analysis in Rabat, Morocco, from; 2005 to 2008. Journal of Epidemiology and Public Health 2015; 63: S83-S84.

[3] Dugue PA, Lynge E, Rebolj M. Mortality of non-participants in cervical screening: Register-basedcohortstudy. Int J Cancer, 2014; 134 (11):2674-2682.

[4] Bosch F, Broker T, Forman D. Comprehensive Control of Human Papilloma virus Infections and Related Diseases 2013, Vaccine ; 31:1-31.

[5] Cannistra S, Niloff JM. Cancer of the uterine cervix, in New England Journal of Medicine, 1996; 334 (16):1030-1038.

[6] The government's policy of "de-amalgamation" is a key part of the government's policy of "de-amalgamation" and "the right to development". The government's policy of "de-mining" is to be used to support the government's policy of "de-mining" and to "take action" to support the government's policy of "de-mining" the country. 7(4).168-172. 
[7] Hammouda D, Muoz N, Bouhadef A, Oublil M, Franceschi S. Epidemiology of human papillomavirus infection in Algeria Eurocancer. John libbey Euro text, 2008; 163-166.

[8] Solomon D, Schiffman M, Tarrone. Comparison of three management stratigies for patients with atypical squamous cells of undetermined significance.J Natl Cancer Inst 2001; 93:293-9.

[9] Sherman ME, Solomon D, Shiffman M. Qualification of ASC-UC: a comparison of equivocal LSIL and equivocal HSIL cervical cytology in the ASC-US LISL Triage Study (ALTS), Am J Cl Pathol; 2001; 117(1):96-102.

[10] Baba samaké. Precancerous and cancerous lesions of the cervix at CS Ref of the discri v and BAMAKO; 2010.

[11] Soudre BR, Lamien A, Kone B, Sanou M, Akande S. Lesions precancerous and cancerous from the cervix to the burkinafaso. Cytologic study conducted in two provinces (Oudalan, Seno). Black African Medicine: 39 (12).

[12] Lansac J, Lecomte P, Marret H. Gynecology for practitioner; Paris: Masson ed, 1992; 2002:75-98.
[13]Clarke B, Chetty R. Postmodern cancer: the role of human immunodeficiency virus in uterine cervical cancer. Molecular Pathology 2002; 55(1):19-24.

[14]Coker AL, Pope BO, Smith PH, Sanderson M, Hussey JR (2001). Assessment of clinicalpartner violence screening tools. JAMWA 2001; 56:19-23.

[15] Tebeu Pm Sandjong I, N'kele N And Coll . Pre-cancerous lesions of the cervix in rural areas: Cross-sectional study. Med Afr Noire $2005 ; 52: 27-31$.

[16] Briton LA. Oral Contraceptives and cervical néoplasie .contraception 1991; 43(6):581-95.

[17] El Gnaoui N, Saile R, Benomar H. Cervical smear a must-have test for cervical lesions J Afr Cancer 2010; 2:9-13

[18] Monsonego J. Cervical Cancer Prevention: Issues and Prospects of Papilloma virus Vaccination. Gynecol Obstet 2006; 34:189201. (Consulted November 1, 2013)

[19] Eeckeleers P. General Practitioner's Place in cervical cancer and HPV infection screening. GMR 2005; 222:176-179 